
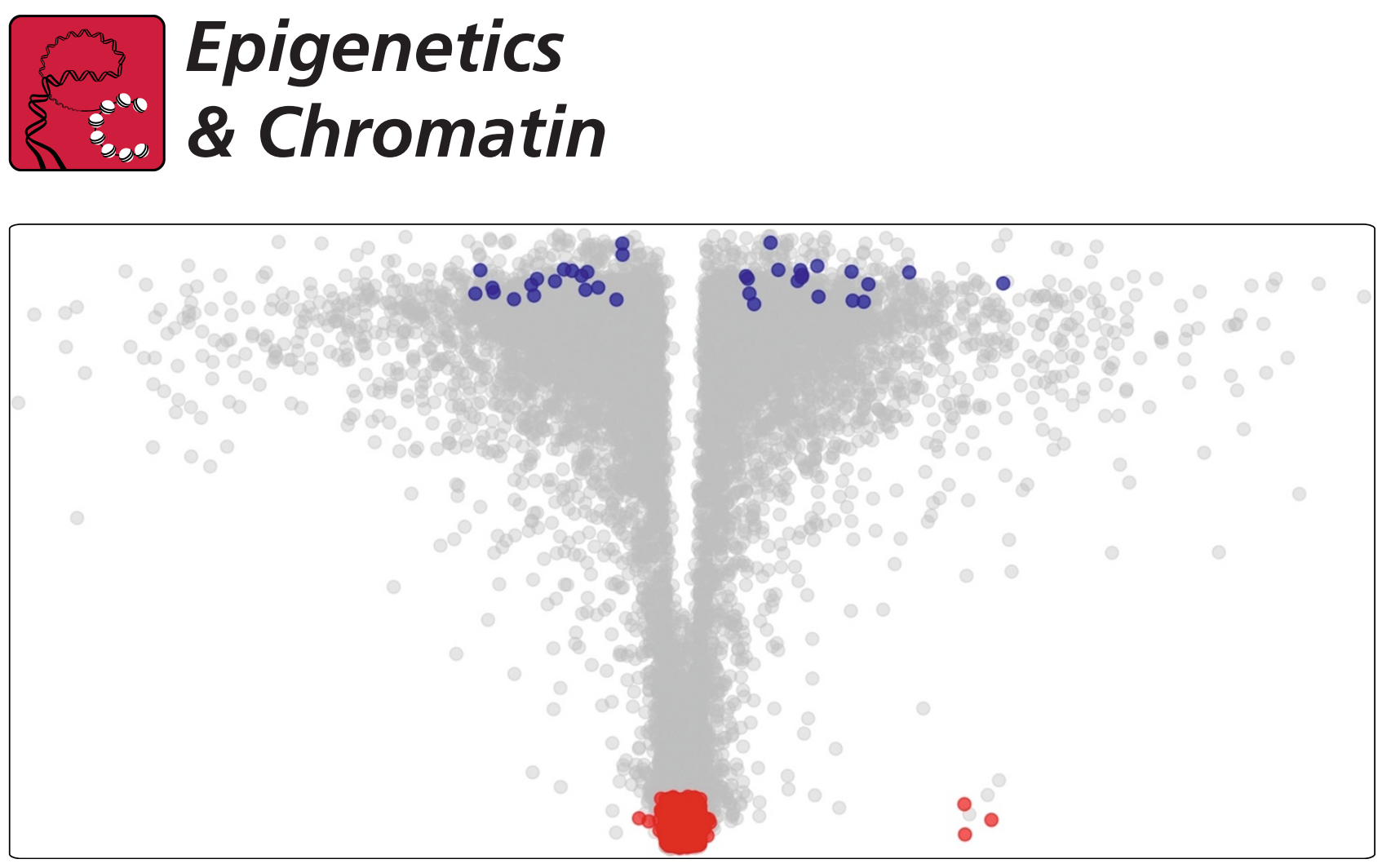

Meta-analysis of human methylomes reveals stably methylated sequences surrounding $\mathrm{CpG}$ islands associated with high gene expression Edgar et al. 


\title{
Meta-analysis of human methylomes reveals stably methylated sequences surrounding CpG islands associated with high gene expression
}

\author{
Rachel Edgar ${ }^{1,2}$, Powell Patrick Cheng Tan², Elodie Portales-Casamar ${ }^{2}$ and Paul Pavlidis ${ }^{2 *}$
}

\begin{abstract}
Background: DNA methylation is thought to play an important role in the regulation of mammalian gene expression, partly based on the observation that a lack of $\mathrm{CpG}$ island methylation in gene promoters is associated with high transcriptional activity. However, the $\mathrm{CpG}$ island methylation level only accounts for a fraction of the variance in gene expression, and methylation in other domains is hypothesized to play a role. We hypothesized that regions of very high stability in methylation would exist and provide biological insight into the role of methylation both within and outside CpG islands.

Results: We set out to identify highly stable regions in the human methylome, based on the subset of CpGs assayed with an Illumina Infinium $450 \mathrm{~K}$ array. Using 1,737 samples from 30 publically available studies, we identified 15,224 CpGs that are 'ultrastable' in their state across tissues and developmental stages (974 always methylated; 14,250 always unmethylated). Further analysis of ultrastable CpGs led us to identify a novel subset of CpG islands, 'ravines', which exhibit a markedly consistent pattern of low methylation with highly methylated flanking shores and shelves. We distinguish ravines from other CpG islands characterized by a broader flanking region of low methylation. Interestingly, ravines are associated with higher gene expression compared to typical unmethylated $\mathrm{CpG}$ islands, and are more often found near housekeeping genes.

Conclusions: The identification of ultrastable sites in the human methylome led us to identify a subclass of CpG islands characterized by a very stable pattern of methylation encompassing the island and flanking regions, established early in development and maintained through differentiation. This pattern is associated with particularly high levels of gene expression, providing new evidence that methylation beyond the CpG island could play a role in gene expression.
\end{abstract}

\section{Background}

Variation in the methylation state of DNA across cell types, developmental stages and physiological or disease conditions is of intense interest to understanding mammalian gene regulation. To this end, numerous studies have been carried out to measure DNA methylation states among cell types or conditions at the resolution of single cytosine guanine dinucleotides (CpGs). Currently, the field is undergoing an explosion of characterization of methylomes, leading to a growing but still highly incomplete understanding of the relationships among methylation, gene

\footnotetext{
*Correspondence: paul@chibi.ubc.ca

${ }^{2}$ Centre for High-Throughput Biology and Department of Psychiatry, University of British Columbia, 2890 E Mall, Vancouver, BC V6T 1Z4, Canada Full list of author information is available at the end of the article
}

expression, normal cellular function and disease [1]. The conceptually simplest approach is to divide chromosomes into domains or clusters of similar methylation states and correlate such domains with the location of genes or their regulatory sequences, and with other epigenetic marks such as histone acetylation or methylation. However, even with massive efforts such as ENCODE [2], numerous gaps in our knowledge exist, particularly in the variation (and functional significance) of epigenetic states across multiple cell types and conditions.

Early studies focused on CpG islands (CGIs), defined as short (approximately $1 \mathrm{~kb}$ ) regions of high $\mathrm{CpG}$ density in an otherwise CpG-sparse genome [3]. Many CGIs are associated with gene promoters $[4,5]$, and methylation at CGIs is associated with repression of transcription [6,7]. 
More recently, the utility of the concept of the CGI has been challenged as it has become more technologically feasible to directly measure methylation, rather than relying on inferred states based on CpG density [8]. Genomewide analysis has thus helped define a growing geography of biologically significant methylation patterns besides that associated with CGIs near promoters. CGI 'shores', defined as the $2 \mathrm{~kb}$ of sequence flanking a CGI, have been reported to be more dynamic than the CGI itself $[9,10]$. Beyond shores are 'shelves' [11] and 'open sea' sites [12]. More recently, large DNA methylation 'valleys' and 'canyons' of low methylation have been identified [13-15]. Other domains, identified in tumor cells, are termed 'low-methylated regions' (LMRs) and 'long-range epigenetic activation' (LREA) or silencing (LRES) domains of relatively low or high methylation [16-18]. We note that the definition of these domains inevitably relies on investigator-specified parameters of length and methylation level, and they are not mutually exclusive; for example, canyons often overlap CGIs. In addition, the relative stability of domains such as LREAs and canyons across cell types and conditions is still not completely documented.

In general, the largest changes in DNA methylation are seen during development, which involves global methylation erasure and reestablishment [19], and in cancer, which is characterized by extensive and often gene-specific changes compared to normal tissues [20]. Beyond this, many studies have emphasized the general stability of the methylome. Even between different tissues or tumor types, the number of differentially methylated CpGs reported ranges from $0.5 \%$ to $20 \%$ (depending in part on the statistical tests and significance cut-offs; $[21,22])$. Understanding which sites and domains are relatively static or dynamic is an important step to assigning function to DNA methylation.

Because many previous studies focused on differences in methylation across conditions or cell types, there is likely to be additional information on stability waiting to be identified. Here we analyze a large collection of DNA methylation data to identify a set of ultrastable CpG sites. We associate many of these sites with a novel subset of CGIs we refer to as 'ravines', which tend to be near housekeeping genes and associated with high expression activity and open chromatin states. We propose a new classification of CGIs that takes into account the methylation state of the island as well as the shores and shelves.

\section{Results}

\section{Ultrastable DNA methylation sites}

Our initial analysis was to identify CpGs that have a consistent methylation state, across all available tissue, developmental stage and disease variation. To do this, we took advantage of the large amount of data available from the Illumina Infinium HumanMethylation450 BeadChip (450 K) [11]. The $450 \mathrm{~K}$ assays $485,577 \mathrm{CpGs}$ in the human genome and is widely used in methylation studies, many of which are publicly available through the Gene Expression Omnibus (GEO; [23]). Careful quality control (see Methods) yielded a set of 1,737 samples from 30 different GEO series (a series typically reflects a single publication, [see Additional file 1: Table S1]), covering 26 tissue types and a wide range of conditions (Figure 1A and [see Additional file 1: Table S2]). We used a simple but stringent computational approach to identify candidate CpGs that were consistently methylated or unmethylated in all samples (see Methods). Based on this analysis, 974 CpGs were considered consistently methylated in every sample and 14,250 consistently unmethylated (Figure 1B, [see Additional file 1: Table S3 and Additional file 2]). Together, we refer to these as 'ultrastable' CpGs. These represent $3.1 \%$ of the CpG sites measured on the 450 K. A less stringent definition of 'ultrastable' would expand this set, but for our initial analysis we considered these as our starting pool.

One concern is that the apparent stability of a $\mathrm{CpG}$ might be a function of the platform and methodology. We therefore checked the methylation state of the ultrastable CpGs in the ENCODE reduced representation bisulfite sequencing (RRBS) data as validation. The 1.2 million CpGs measured in the ENCODE RRBS data include 17\% of the sites assayed by the $450 \mathrm{~K}$, including 5,063 (33\%) of the ultrastable CpGs. Of the 121 ultrastable methylated and 4,942 ultrastable unmethylated CpGs of interest for which there was data available in ENCODE RRBS data, $80 \%$ and $98 \%$ were methylated and unmethylated, respectively, in $90 \%$ of RRBS samples [see Additional file 1: Figure S2]). The agreement of ENCODE RRBS data with our results was correlated with sequencing depth, so that higher-quality ENCODE sites tended to agree more closely with our methylation calls (that is, failures to verify tended to be poorly-covered sites in the ENCODE data). This suggests that the large majority of the ultrastable CpGs are not merely artifacts of the $450 \mathrm{~K}$. We further tested whether these CpGs might be giving erroneous measurements due to unusual resistance or sensitivity to bisulfite conversion [24], which is used both by the $450 \mathrm{~K}$ and RRBS methods. We examined the status of CpGs assayed on the $450 \mathrm{k}$ in methylationsensitive restriction Enzyme Sequencing (MRE-Seq; which extracts unmethylated regions of the genome) and methylated DNA immunoprecipitation sequencing (MeDIP-Seq; which extracts methylated regions of the genome) data as neither technique involves a bisulfite conversion. We found that the ultrastable unmethylated CpGs have a significantly higher average read count in the MRE-Seq data than the other $450 \mathrm{~K} \mathrm{CpGs}(P<0.001)$, confirming their stably unmethylated status. Similarly, the ultrastable 


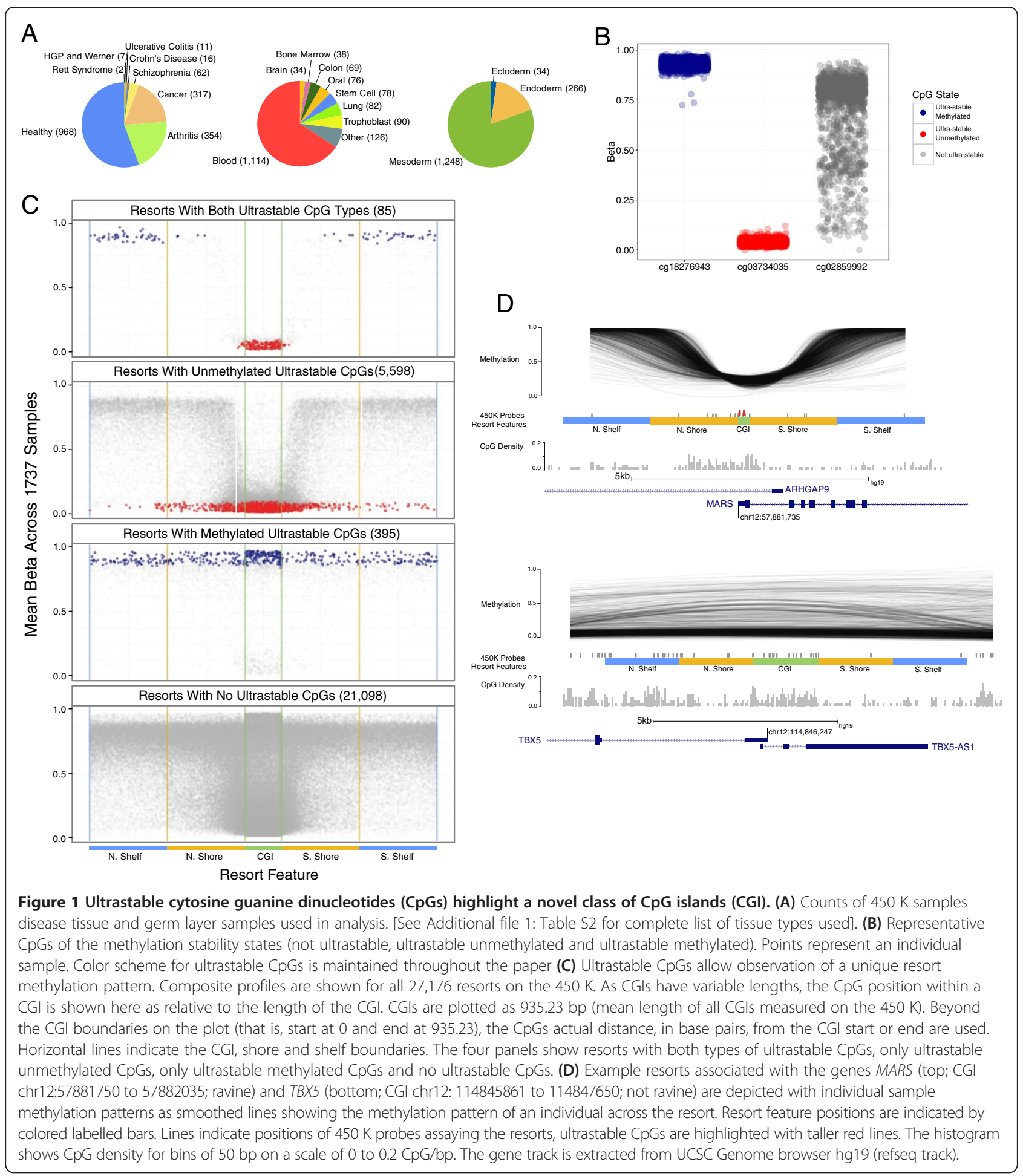

methylated CpGs had a significantly higher average read count in the MeDIP-Seq than the other $450 \mathrm{~K}$ CpGs $(P<0.01)$, confirming their stably methylated status. This analysis confirms that ultrastable $\mathrm{CpGs}$ are seen in both bisulfite-treated and non-bisulfite treated data [see Additional file 1: Figure S3]. Additionally, we examined the ultrastable $\mathrm{CpGs}$ in data sets that purposefully manipulated methylation, either by direct enzymatic treatment of the DNA, or by genetic knockout of DNA methyltransferases. This analysis showed that under appropriate conditions, the ultrastable sites can be measured in their opposite state. This suggests that 
there is no inherent problem with the ultrastable CpGs being measured at either methylation state, but that under a wide range of biological conditions, the CpGs are always in one state.

\section{Distribution of ultrastable cytosine guanine dinucleotide sites in the human genome}

Because the ultrastable sites are consistent across a wide range of tissues, developmental stages and conditions, we hypothesized they would be of biological significance. Both classes of ultrastable sites tend to be near transcription start sites (TSS; $P<0.001, t$-test; accounting for the distribution of sites on the $450 \mathrm{~K}$; [see Additional file 1: Figure S5]). Concomitantly, ultrastable CpGs tend to be associated with CGIs. Of all $450 \mathrm{~K}$ CpGs assayed, 62\% are CGI-associated (in CGI, shore or shelf), while $95.5 \%$ of the ultrastable CpGs are CGI-associated. We also observed that ultrastable CpGs tend to be found in CGIs in groups of two or more, rather than in isolation, more often than expected by chance [see Additional file 1: Figure S6]). The ultrastable unmethylated CpGs are overrepresented in CGIs, rather than in shores and shelves. In contrast, ultrastable methylated CpGs are underrepresented in CGIs but overrepresented in CGI shelves [see Additional file 1: Figure S7]. This distribution is expected as CpGs in CGIs are generally unmethylated and those in the rest of the genome tend to be methylated. However, the extreme stability of these sites led us to hypothesize that the ultrastable CpGs might reflect other features of the CGIs they associate with, leading us to focus further investigation on CGIs. We leave a deeper analysis of the 1,134 non-CGIassociated ultrastable sites as a topic for future study.

\section{Profiles of regions containing ultrastable CpG sites}

We stratified CGIs and their associated flanking shores and shelves into four categories based on the presence or absence of an ultrastable CpG. For brevity, following the terminology of [25], we use the term 'resort' to refer to the complex of a CGI and its flanking shores and shelves. We created a methylation profile for each resort category by aligning the CGIs, shores and shelves and plotting the mean methylation level of each $\mathrm{CpG}$ assayed in the resorts (see legend to Figure $1 \mathrm{C}$ and Methods). As shown in Figure $1 \mathrm{C}$, an interesting pattern emerges. Resorts that contain at least one methylated and unmethylated ultrastable CpG (top panel) have a strikingly high contrast between the low methylation level of the CGI compared to the highly methylated shores and shelves. In comparison, resorts that lack ultrastable CpGs do not show this pattern (bottom panel), and such resorts the CGI can be either methylated or unmethylated, as can be the shores and shelves. Resorts that have only methylated or unmethylated ultrastable sites show an intermediate pattern (middle panels). To get a better sense of the correlation structure of methylation levels across single resorts, we visualized the data at sample-level for two characteristic resorts (Figure 1D). Generally, and in the examples shown, resorts with high contrast between CGI and shore/shelf show a very consistent pattern across samples whereas others do not. By analogy to the previously reported methylation 'valleys' and 'canyons' $[14,15]$, we refer to the sharp pattern shown in Figure 1D top panel as a 'ravine.' We note that ravines genomic positions do not overlap with canyons or valleys (in addition to being smaller; ravines average $785 \mathrm{bp}$ of unmethylated region, canyons $>3.5 \mathrm{~kb}$ and valleys $>5 \mathrm{~kb}$ ). Because gene body methylation has been previously reported to be positively correlated with gene expression [26,27], we further tested whether the super-additive effect we observe could be explained by a ravine being equivalent to a CGI next to a highly methylated gene body. This appears to not be the case as ravines are symmetrical with respect to transcription direction, and ravines can be found away from gene bodies [see Additional file 1: Figure S8]. A further extensive comparison of ravines to a number of previouslydefined methylation domain types shows that ravines represent a novel aspect of the methylome [see Additional file 1: Table S4]. To confirm our findings were not due to some idiosyncrasy of the set of $450 \mathrm{~K}$ samples or the parameters we used to define ravines, we tested whether the ravines had the same properties on an additional set of 757 samples of similar variety, which became available after we started our study [see Additional file 1: Table S5 and Figure S9]. The results show that the CGIs we classify as ravines, whether uniformly unmethylated or 'other,' have the same features in the new data set, strongly supporting the idea that ravines are stable features of these genomic regions.

\section{Ravines are associated with active transcription}

To identify ravines more comprehensively, we quantified the difference between the CGI and shore/shelf methylation levels ('steepness') for all $450 \mathrm{~K}$ resorts. In this manner we ranked all 27176 resorts assayed on the $450 \mathrm{~K}$ for their 'ravine-ness', independent of whether they contained an ultrastable CpG. As depicted in Figure 2A, the 1,500 resorts with steepest ravines (mean steepness 0.638 ) represent the most extreme ravine pattern (hereafter referred to as 'steep ravines') whereas the 1,500 unmethylated resorts with the lowest ravine steepness (CGI mean methylation $<0.3$ and mean steepness 0.097 ) show a more uniform pattern (hereafter referred to as 'uniformly unmethylated resorts,' mean methylation and CpG density of resorts [see Additional file 1: Table S6]).

To test whether the high methylation in the shores had an impact on the associated gene expression, we used the ENCODE DNase-sequencing data [2] as an indirect measure of non tissue-specific transcriptional activity. 


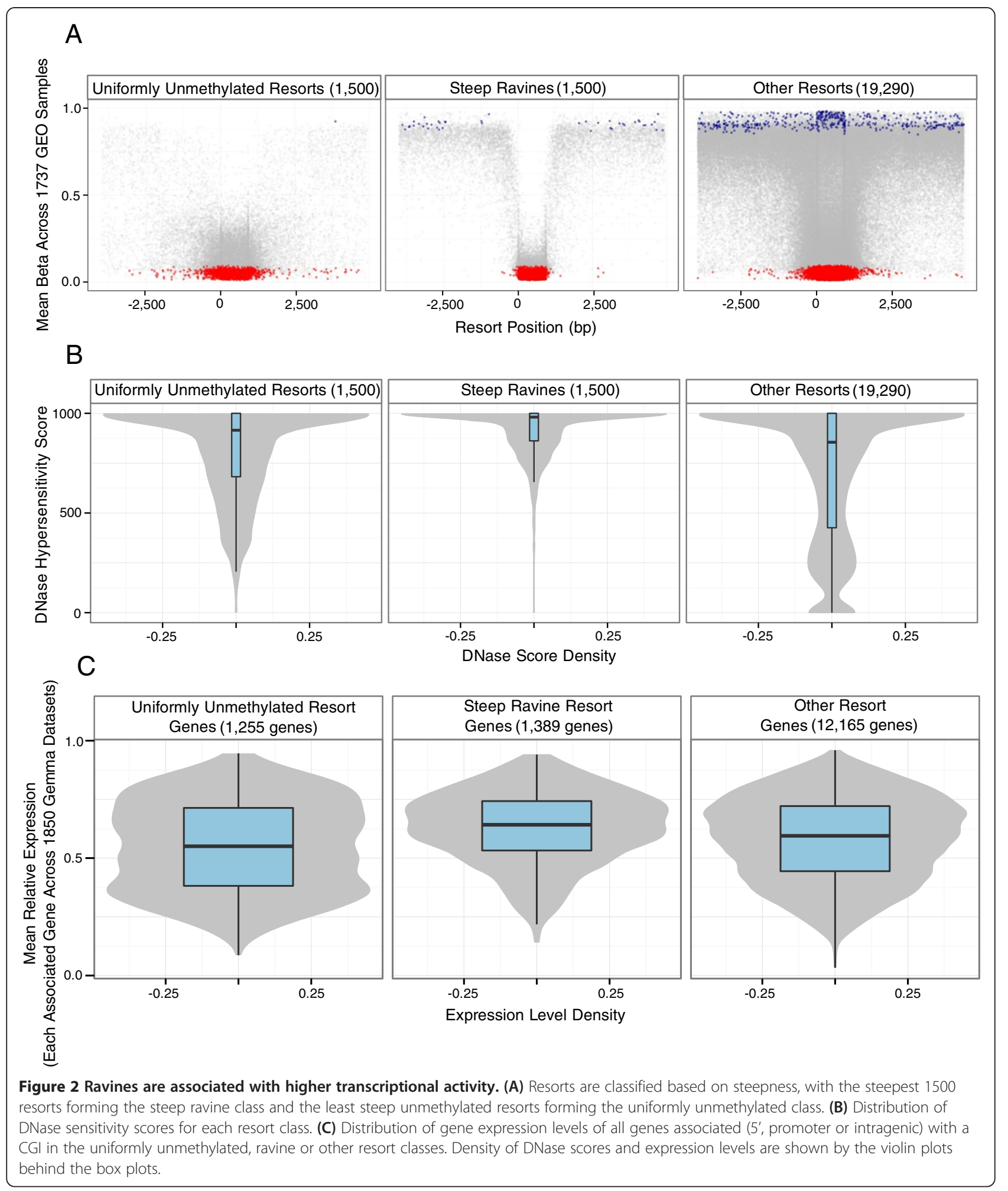

Unmethylated CGIs are generally associated with high transcriptional activity at their associated gene [7]. As expected, uniformly unmethylated resorts show significantly $(P<0.001$, Wilcoxon rank sum (Wilcoxon RS) test) higher DNase sensitivity than all other resorts. Interestingly, the steep ravines show significantly $(P<0.001$, Wilcoxon $\mathrm{RS}$ test) higher DNase sensitivity than the uniform resorts (Figure 2B). Since the main difference between the steep ravines and the uniformly unmethylated resorts is the highly methylated shores and shelves, it suggests that this 
high methylation on the edges of CGIs facilitates a transcriptionally permissive state. The relationship between high ravine steepness and high transcriptional activity is supported by analysis of a diverse set of microarray expression experiments (see Methods). Averaged across expression data sets, the expression of genes associated with steep ravines is significantly higher $(P<0.001, t$-test $)$ than for the uniformly unmethylated resorts (Figure $2 \mathrm{C}$ ).

We next tested whether the steepness of ravines was predictive of gene expression, beyond that which is possible using methylation level of the CGI alone, using a regression approach (see Methods). Gene expression variance $\left(R^{2}\right)$ explained by CGI methylation level alone is $4.6 \%$, comparable to previous reports $[28,29]$ even though our expression and methylation data comes from different sources. Variance in expression levels explained by resort steepness alone is $3.4 \%$. In combination, ravine steepness and CGI methylation level explain $9.8 \%$ of the expression variance, significantly greater than would be expected if they were purely additive (significant interaction, $P<0.001$, ANOVA).

The association of ravines with high transcriptional activity was also supported by ENCODE RNA polymerase II binding data (POLR2A; [2], [see Additional file 1: Figure S10]). Active transcription of ravine associated genes is not explained by changes in histone marks as ravine CGIs show no significant differences in the 12 histone marks measured by ENCODE ([2]; [see Additional file 1: Figure S11]). However, uniformly unmethylated resorts do show significant differences in H3k27me3 and H3k4me1 marks $(P<0.001$, Wilcoxon RS test; [see Additional file 1: Figure S11]).

\section{Ravines are associated with housekeeping genes}

Taken together, the consistency of the ravine pattern, high DNase sensitivity and high associated gene expression, both across a variety of tissues and conditions suggests the genes associated with steep ravines are universally active in human cells. Indeed, we find that steep ravineassociated genes are significantly associated with a curated set of housekeeping genes $(P<0.001$, Fishers exact test; Figure 3), but not with tissue-specific genes [30]. In contrast the uniformly unmethylated resorts are not significantly associated with either set of genes (Figure 3). However uniformly unmethylated resorts are over represented for gene ontology (GO) groups for development and disease ontology (DO) groups for development

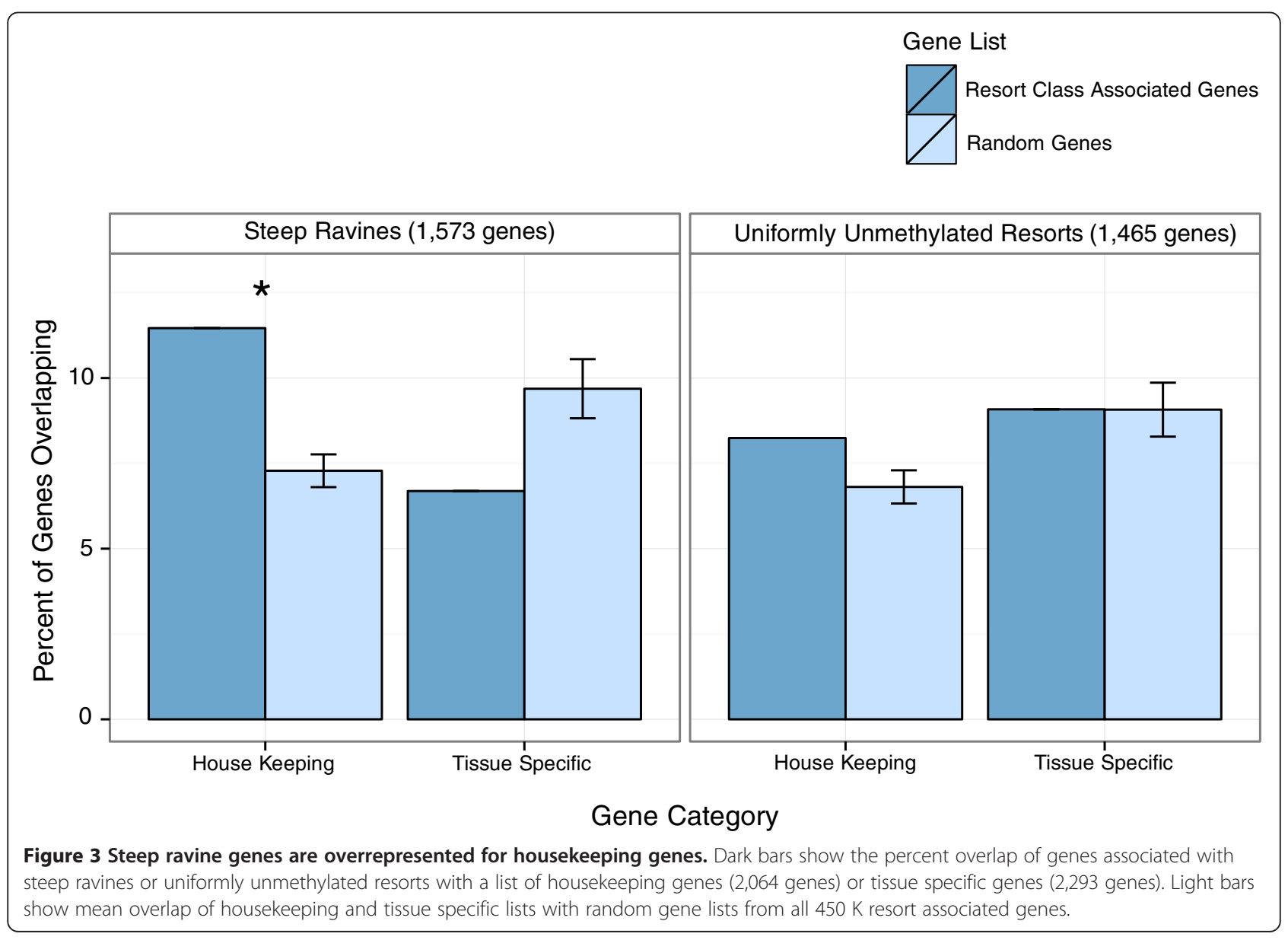


associated diseases ([31]; [see Additional file 1: Tables S7 and S8]). Ravine associated genes had no significant enrichment for GO groups or diseases. Suggesting that ravines, which are maintained across tissues and conditions, may be regulatory features associated with the expression of ubiquitous genes, while uniformly unmethylated resort associated genes function in development.

\section{Discussion}

Our contributions in this paper are twofold. First, we identified a subset of CpGs in the human genome that appears to be highly stable in their methylated or unmethylated state, across diverse developmental states and cell types. Second, we identified a subclass of CGIs that have an unusually high contrast between the methylation state of the CGI and the flanking shores. We found that such CGIs tend to be found near highly expressed genes. While the $450 \mathrm{~K}$ array only measures a subset of CpGs in the human genome, our results are consistent with a role for shore methylation in the regulation of genes which are 'always on'.

The existence of CpGs with ultrastable methylation states reveals a previously undocumented feature of the human methylome. While some level of stability has been previously noted in differentiated somatic cells, the dramatic changes in methylation during development and differences between tissues [32] suggested that much of the methylome is dynamic. In contrast, our analysis suggests that a subset of the human methylome is highly stable across differentiated cell types, cancer cells, embryonic stem cells, induced pluripotent stem cells, trophoblasts and germ cells. The consistency of the CpGs across our developmental and germ cell samples suggests the state of the sites we found to be ultrastable are established early in development and then maintained in all studied differentiated tissues.

We cannot rule out the possibility that some of the ultrastable CpGs we identified will have a different state in some cell type or physiological state not yet examined. However, the data set we have assembled covers many of the states previously identified with variability, including between tissues [22], developmental states [9] and diseases [13,33]. Indeed, we suspect there are many other CpGs in the human genome that show unusual stability but not revealed by our study. Our analysis used a very stringent threshold, disallowing even single exceptions; additional CpGs are 'nearly stable.' Furthermore the $450 \mathrm{~K}$ array does not assay most of the CpGs in the genome, some of which are likely to also be ultrastable. As there are only a few samples of certain tissue types, we could not assess the potential existence of tissuespecific ultrastable CpGs. Future experiments to assess additional $\mathrm{CpGs}$ and larger numbers and varieties of samples will help further elucidate the scope of ultrastable CpGs.
Our association of ultrastable CpGs with TSSs and resorts (94.5\% in resorts) agrees with the previous observations that differentially methylated (that is, dynamic) regions are primarily located far from the TSSs, outside of resorts [22]. However, we note that the $450 \mathrm{~K}$ array is biased towards resort CpGs. The small subset of ultrastable CpGs we observe that are not in resorts (5.5\%) hints that many other ultrastable CpGs may be outside resorts. Because most of the CpGs we identified are in or near resorts, we focused our analysis on their potential roles in resort function. Regarding the ravine pattern, we note that some degree of contrast between shores and CGIs is expected: the majority of CpGs are known to be methylated, with CGIs being the exception. However, we show that this contrast is not observed in all resorts, and is particularly striking in resorts that also contain ultrastable unmethylated CpGs. The association of steep ravines with higher gene expression levels, high DNase I sensitivity and high POLR2A occupancy provides a novel and biologically meaningful classification of human CGIs that complements earlier efforts [5].

In our study (as in many others), we attempted to relate the methylation state of a region to the expression level of nearby genes. However, it is not clear how to tell if a CGI is in a position to influence (or be influenced by) a gene. The examination of ravines may provide some insight. The classic association of genes with CGIs is based on the presence of a CGI in a gene's $5^{\prime}$ promoter. This association is sufficiently strong that it was originally used to annotate human genes [34]. However, many CGIs do not appear to function as $5^{\prime}$ gene promoters ([35]; [see Additional file 1: Figure S12]). In contrast, the ravine CGIs are more strongly overrepresented in $5^{\prime}$ promoter regions of genes. Thus ravines fit the classic CGI archetype: an unmethylated CGI in $5^{\prime}$ promoter of a highly expressed gene. Ravines share an additional feature in common with the classical CGI, an association with housekeeping genes [36,37]. The image of unmethylated $5^{\prime}$ promoter CGIs leading to gene expression may be more specific to ravines and not true for resorts and CGIs in general. A stable ravine pattern at many $5^{\prime}$ promoters supports the emerging idea that it is crucial to examine non-promoter CpGs and CGIs in differential methylation analysis as nonpromoter regions may have more dynamic methylation than $5^{\prime}$ promoter regions.

While CGIs are the classic unit of focus for human methylation studies, other groups have focused on identifying other types of methylation domains [14-18] that have some overlap with CGI classes we identified. Specifically, uniformly unmethylated resorts (non-ravines) are encompassed by canyons and valleys $[14,15]$ more than other resorts, suggesting that uniformly unmethylated resorts, canyons and valleys may be related domains 
[see Additional file 1: Table S4]. Subsets of canyons and valleys lack H3k27me3 similar to uniformly unmethylated resorts. Additionally, uniformly methylated resorts, canyons and valleys are all enriched for genes which function in development. Thus uniformly unmethylated resorts are confirmation of canyons and valleys as features of the methylome in a greater variety of tissues. Ravines on the other hand minimally overlap with canyons, valleys or most other previously defined methylation domains. Additionally ravines show no obvious relation to histone marks. Other regulatory mechanisms are likely be involved which explain ravine association with stable and high gene expression.

One of our observations is that across a wide range of tissue types and developmental stages, DNA methylation flanking CGIs is positively correlated with gene expression, especially when the CGI has a very low methylation level. Previously, positive correlations between shore methylation and gene expression have been reported in some studies. Hansen et al. [38] and VanderKraats et al. [39] found tissue-specific ravine-like patterns emerging between cancer and healthy states as a differential methylation signature. This suggests that ravines might not just be a static feature associated with housekeeping genes, but one that can be generated under different conditions. While our manuscript was under review, Lou et al. [40] reported gene body methylation changes associated with increases in gene expression, a pattern that may also have a relationship to the ravines we observed. Although the association they saw was specifically in blood and limited to a family trio, it is further evidence that ravine-like patterns are positively correlated with gene expression. Another potentially relevant study showing a pattern similar to our ravines, from $\mathrm{Wu}$ et al. [41], found that the shores and shelves of unmethylated $5^{\prime}$ promoter CGIs, are associated with high Dnmt3a activity in the mouse genome. Wu et al. also found Dnmt3a- shore and shelf DNA methylation is associated with increased gene expression. We hypothesize that the regions identified by Wu et al. may correspond to ravines, but we were unable to confirm this with the information available. We speculate that possible Dmnt3a activity at steep ravines' shores and shelves could function to antagonize the binding of transcriptional repressors. The previous work on Dnmt3a binding at gene promoters also found that shore and shelf methylation in proximal promoters antagonized polycomb protein-binding [41]. Interestingly, uniformly unmethylated resorts had a higher association with polycomb binding sites than steep ravines ([42]; [see Additional file 1: Polycomb Binding Sites]). On the other hand, we did not find evidence that ravines are associated with low H3k27me3, as would be predicted from polycomb binding inhibition [see Additional file 1: ENCODE Histone Modifications]. To resolve the function of ravines, it will be important to further explore their relationship with polycomb binding and other regulatory mechanisms.

An alternate model for ravine function is that transcription factors that bind methylated CpGs could be directly affected by shore and shelf methylation. However, most studies of methyl-CpG-binding proteins show they function to repress gene expression, agreeing with the classical model of any methylation in promoters being repressive [7]. There is, however, recent evidence of the methyl-CpG-binding protein MeCP2 having transcription activating function at promoters with methylated CpGs [43]. A model where MeCP2 binds methylated shores at gene promoters and performs its transcription activation function could explain the association of methylated shores and shelves with high gene expression.

\section{Conclusions}

In summary, ravines are a novel subset of CGIs, distinct from previously identified methylome domains. The ultrastable $\mathrm{CpGs}$ and ravine consistency across samples suggests they are stable component of the human methylome. While the ravines suggest that CGI shore methylation is stably associated with high gene expression, other work has shown some CGI shores methylation to be highly dynamic. Both results support the overall importance of shores for gene expression. The presence of ravines in the 5 ' gene promoters of many actively transcribed genes supports a complex role for methylation in both activating and repressing expression.

\section{Methods}

\section{Data collection}

As of 30 April 2013, 58 unique sample series run on the Illumina $450 \mathrm{~K}$ platform (GPL13534 or GPL16304) were available in the Gene Expression Omnibus (GEO) [23]. Using the $\mathrm{R}$ Bioconductor package 'GEOquery' 2.26.2 [44], the series were collected and considered for quality control [see Additional file 1: Table S1]).

\section{Quality control}

To qualify for inclusion in our study, samples had to have beta values for all 485,577 probes, disqualifying 19 series. An additional four studies that involved direct global manipulation (genetic or chemical) of DNA methylation were also removed (DNMT1; DNMT3b double knockouts or methyltransferase treatment). Five more series were considered unsuitable for the metaanalysis, for individual reasons, and removed (that is, mislabeled data, high amount of missing data in all samples, multiple arrays grouped together, etcetera; see Additional file 1: Individual Study Quality Control for details of data exclusion justifications). Within each 
study, individual samples were further assessed for quality. Eight samples with unusually high numbers of missing values ( $5 \mathrm{SD}$ from the mean, corresponding to $>0.4 \%$ or 1957 were removed.

\section{Ultrastable cytosine guanine dinucleotide calling}

A three-component mixture model was fit to each series beta distribution using the $\mathrm{R}$ 'mixtools' package [45]. The mean was calculated for each component; $\mu+2$ sd and $\mu-2$ sd were used as the unmethylated and methylated beta value thresholds, respectively, for each series separately [see Additional file 1: Figure S1]. For each sample, unmethylated and methylated probes were called based on the thresholds computed for the series. Typical thresholds were near beta values of 0.2 and 0.8 . Probes that were scored as methylated or unmethylated in all 1,737 samples were deemed 'ultrastable.'

\section{ENCODE confirmation of ultrastable cytosine guanine dinucleotides}

Data from 102 ENCODE RRBS samples was collected from UCSC (Release 3 of ENCODE/HudsonAlpha RRBS data; [2]). In many RRBS studies, reads with $<10$ fold coverage $[46,47]$ are discarded; therefore, a ten-fold coverage cutoff was used on the ENCODE RRBS data. CpGs were considered methylated in ENCODE RRBS data if their percent methylation was $>80$ and unmethylated if the CpG percent methylation was $<20$ [see Additional file 1: Figure S2].

\section{Methyltransferase confirmation of ultrastable cytosine guanine dinucleotides}

Four methyltransferase $450 \mathrm{~K}$ studies (DNMT1; DNMT3b double knockouts, methyltransferase inhibitor or methyltransferase treated) with a total 68 samples were available on GEO [see Additional file 1: Table S1]. The studies were excluded from the ultrastable site calling, and the states of the ultrastable sites were then checked in the 68 samples.

\section{MRE-Seq and MeDIP-Seq confirmation of ultrastable cytosine guanine dinucleotides}

From the NIH Roadmap Epigenomics Mapping Consortium data [48] 7 MRE-Seq and 7 MeDIP-Seq samples were used from seven tissue types (GSM669604, GSM669614, GSM543007, GSM543021, GSM669600, GSM669610, GSM543009, GSM543023, GSM707017, GSM941725, GSM428286, GSM456941, GSM543013, and GSM543027). Due to computational constraints, here we present data for chromosome 20 (analysis for other chromosomes is a work in progress). For the 10,379 $450 \mathrm{~K} \mathrm{CpGs}$ on chromosome 20 the reads covering a $\mathrm{CpG}$ seen in either technique were averaged across samples. The average number of reads across samples, from either technique, is used as the signal of methylated (MeDIP-Seq) and unmethylated (MRE-Seq) of a CpG. A Wilcoxon Rank Sum (Wilcoxon RS) test was used to test the significance of the difference between ultrastable sites on the array and non-ultrastable sites on the array.

Ultrastable cytosine guanine dinucleotide characterization To annotate the CpGs, we used three sources of information. The first was that provided by Illumina [11] and included UCSC CGI a CpG site is associated with and the CGI relation. CpG shores and shelves are defined by base pairs from the UCSC defined CGI start and stop coordinates. Shores are $2 \mathrm{~kb}$ from the CGI boundaries [10], and shelves are 2 to $4 \mathrm{~kb}$ from the CGI boundary [11]. The second annotation, available on GEO under GPL16304, contains additional probe annotations to those provided by Illumina under GPL13534 [49], including distance to nearest TSS. A Student's $t$-test was performed to determine significantly different distance to TSS between all CpGs and ultrastable CpGs.

\section{Composite profile of resorts}

The 27176 resorts have a range of lengths (minimum $201 \mathrm{bp}$, maximum 45,710 bp, mean 935 bp). To allow comparison of resorts, the position of a CpG in a CGI was converted to the CpG's relative position in a CGI of the mean CGI size (935 bp). As an example, a CpG 200 bp from the start of a 1,200 bp CGI would be shown at $155.83 \mathrm{bp}$ from the start of the CGI in the composite plot. Conversion of $\mathrm{CpG}$ position to a relative value allowed comparisons of CGIs of varying sizes. Resort shores include all CpGs less than $2 \mathrm{~kb}$ from the CGI start or end. CGI shelves include all CpGs 2 to $4 \mathrm{~kb}$ from the CGI start or end. Since shores and shelves are fixed sizes $\mathrm{CpG}$ positions within shores and shelves are shown at their actual, not relative, distance from the CGI boundaries.

\section{Resort classifier based on ravine steepness}

Steepness of a ravine was only calculated for those resorts which had at least one CpG measured on the 450 $\mathrm{K}$ array in each relevant part of the result (CGI, the north shore or shelf and the south shore or shelf; 22,290 resorts). Steepness was calculated as mean beta methylation level of the CGI CpGs subtracted from the mean beta methylation of the shore and shelf CpGs. Steep ravines were arbitrarily defined as those with the 1,500 highest steepness values. Uniformly unmethylated resorts were defined as those with a CGI mean methylation $<0.3$ and the 1,500 lowest steepness values.

\section{ENCODE DNase sensitivity data}

ENCODE UCSC DNase clusters track (wgEncodeRegDnaseClusteredV2) from the University of Washington 
and Duke University were collected for 125 cells types [2]. DNase score for a CGI was calculated by taking the score for any DNase hot spot overlapping a CGI body. If multiple DNase hot spots overlapped a CGI, the scores were weighted by the amount of the CGI the DNase peak overlapped. Wilcoxon RS tests on the DNase data were performed among the three classes of resorts.

\section{Cytosine guanine dinucleotide island-to-gene associations}

There are multiple methods of annotating a CGI with a gene association, including the annotation a CGI with closest gene TSS to the CpGs making up a CGI [49], the position of the CpGs making up a CGI in a gene's body or promoter [11], or overlap of an entire CGI with a gene's body or promoter [35]. Each yields a slightly different CGI to gene associations. Even with a given method, a CGI can end up associated with more than one gene [see Additional file 1: Figure S4]. For this study, an inclusive CGI to gene association was used. Genes that overlap a CGI in their promoter or gene body were considered associated with that CGI. An inclusive association was used because the exact role of CGIs and resorts in regulating gene expression is unclear. Using inclusive associations will hopefully capture any possible CGI effects on gene expression.

CGI were considered associated with a gene if the CGI is located in the gene body or in promoter region of a gene. Classifications of CGI in promoters and gene bodies were based of the [35] definitions. Refseq genes were downloaded from UCSC. For Refseq genes with multiple transcripts the longest form was used, to capture any possible intragenic functions. Non-coding RNA (ncRNA) annotations were collected from Ensembl [50]. The final list included 40,721 unique transcription units. There are $21,743 \mathrm{CGI}$ on the $450 \mathrm{~K}$ array associated with 17,725 genes or ncRNA (39\% intragenic CGI, 61\% promoter CGI).

Although gene expression results are subject to noise from incorrect CGI to gene associations, DNase sensitivity data is independent of gene to CGI associations. DNase sensitivity data will capture the effects of methylation on transcriptional activity without absolute gene to CGI associations. Until CGI to gene associations are definite DNase sensitivity data will be valuable to pair with methylation for examining transcriptional activity.

\section{Gene expression data}

Gene expression data from 2,021 GEO expression studies were assembled from the Gemma database [51], representing 97,388 samples and 34 tissue types. Expression information was available for 21,733 genes, 14,809 of which were associated with one of 22,290 $450 \mathrm{~K}$ CGI (only those CGI in resorts previously classed by steepness were compared for expression). Student's t tests on the gene expression data were performed among the three classes of resorts. Linear regression was done with 17,127 CGI (CGI with associated gene expression level and steepness class). Models were for expression variance with associated resort steepness and associated CGI mean methylation, and resort steepness and CGI methylation interaction. An F-test was used to show significant interaction of resort steepness and CGI methylation.

\section{Steep ravine-associated gene function}

List of steep ravine- and uniform resort-associated genes are the same as those used with the gene expression data. One hundred random gene lists of the same length as the steep ravine and uniform resort gene association lists (1,573 and 1,465 , respectively) were generated. Percent overlap of each random gene list and either the housekeeping or tissue-specific list was calculated. Mean overlap of the 100 random lists with the housekeeping and tissue-specific lists were taken as the expected overlap from comparison with the steep ravine and uniform resort gene lists. Fisher's exact tests were performed between each random gene list overlap and steepness class gene lists.

We used the GO annotations of the 19,389 genes associated with the $450 \mathrm{~K}$ probes [11] and disease ontology (DO) terms from the Phenocarta database [31] for enrichment analysis. Enrichment of GO and DO groups in uniformly unmethylated resort- and ravine-associated genes using overrepresentation analysis was done in ErmineJ [52]. Statistical significance is reported as false discovery rates computed using the Benjamini-Hochberg method in ErmineJ. Also calculated are the multifunctionality scores of the ontology gene sets [53], as well as the $P$ values corrected for multifunctionality.

\section{Additional files}

Additional file 1: Supplementary Information. Description of data: Additional analyses, figures and tables.

Additional file 2: Ultrastable CpGs loci. Description of data: Probe_ID is the $450 \mathrm{~K} \mathrm{CpG}$ probe ID given by Illumina. State is the state of ultrastable CpG. Coordinate_37 is the Human Genome Build 37 position. Chromosome_37 is the Human Genome Build 37 chromosome.

\section{Abbreviations}

CDMR: cancer-specific differentially methylated region; CGI: CpG island; CpG: cytosine guanine dinucleotide; CUMR: control unmethylated region; DO: disease ontology; FFPE: formalin-fixed paraffin-embedded; GEO: Gene Expression Omnibus; GO: gene ontology; LMR: low methylated region;

LREA: long-range epigenetic activation; LRES: long-range epigenetic silencing; MeDIP-Seq: methylated DNA immunoprecipitation sequencing; MRE-Seq: methylation-sensitive restriction enzyme sequencing; ncRNA: non-coding RNA; POLR2A: RNA polymerase II; RDMR: reprogramming specific differentially methylated region; RRBS: representation bisulfite sequencing; TDMR: tissue specific differentially methylated region; TFBS: transcription factor binding site; TSS: transcription start sites; UMR: unmethylated region; Wilcoxon RS: Wilcoxon rank sum; $450 \mathrm{~K}$ : Illumina Infinium HumanMethylation450 BeadChip. 


\section{Competing interests}

The authors declare that they have no competing interests.

\section{Authors' contributions}

PPCT assembled and provided the gene expression data from previous studies. RE performed all other data collection and analysis. PP and EPC were supervisory authors and involved throughout the project in concept formation and manuscript edits. All authors read and approved the final manuscript.

\section{Acknowledgements}

We thank Michael Kobor, Martin Hirst, Sanja Rogic, Shreejoy Tripathy, and Magda Price for comments on the manuscript. This work was supported by the Natural Science and Engineering Research Council of Canada CREATE Research Rotation Award to RE; NeuroDevNet Network of Centres of Excellence; and National Institutes of Health GM076990. Funding for open access charge: National Institutes of Health GM076990.

\section{Author details}

${ }^{1}$ Genome Science and Technology Graduate Program, University of British Columbia, 2329 W Mall, Vancouver, BC V6T 1Z4, Canada. ${ }^{2}$ Centre for High-Throughput Biology and Department of Psychiatry, University of British Columbia, 2890 E Mall, Vancouver, BC V6T 1Z4, Canada.

Received: 24 June 2014 Accepted: 6 October 2014 Published: 23 October 2014

\section{References}

1. Jones PA: Functions of DNA methylation: islands, start sites, gene bodies and beyond. Nat Rev Genet 2012, 13:484-492.

2. ENCODE Project Consortium, Bernstein BE, Birney E, Dunham I, Green ED, Gunter C, Snyder M: An integrated encyclopedia of DNA elements in the human genome. Nature 2012, 489:57-74.

3. Gardiner-Garden M, Frommer M: CpG islands in vertebrate genomes. $J \mathrm{Mol}$ Biol 1987, 196:261-282.

4. loshikhes IP, Zhang MQ: Large-scale human promoter mapping using CpG islands. Nat Genet 2000, 26:61-63.

5. Saxonov S, Berg P, Brutlag DL: A genome-wide analysis of CpG dinucleotides in the human genome distinguishes two distinct classes of promoters. Proc Natl Acad Sci U S A 2006, 103:1412-1417.

6. Esteller M: CpG island hypermethylation and tumor suppressor genes: a booming present, a brighter future. Oncogene 2002, 21:5427-5440.

7. Bird A: DNA methylation patterns and epigenetic memory. Genes Dev 2002, 16:6-21.

8. Greally JM: Bidding the CpG island goodbye. Elife 2013, 2:e00593.

9. Doi A, Park IH, Wen B, Murakami P, Aryee MJ, Irizarry R, Herb B, Ladd-Acosta C, Rho J, Loewer S, Miller J, Schlaeger T, Daley GQ, Feinberg AP: Differential methylation of tissue- and cancer-specific CpG island shores distinguishes human induced pluripotent stem cells, embryonic stem cells and fibroblasts. Nat Genet 2009, 41:1350-1353.

10. Irizarry RA, Ladd-Acosta C, Wen B, Wu Z, Montano C, Onyango P, Cui H, Gabo K, Rongione M, Webster M, Ji H, Potash JB, Sabunciyan S, Feinberg AP: The human colon cancer methylome shows similar hypo- and hypermethylation at conserved tissue-specific CpG island shores. Nat Genet 2009, 41:178-186.

11. Bibikova M, Barnes B, Tsan C, Ho V, Klotzle B, Le JM, Delano D, Zhang L, Schroth GP, Gunderson KL, Fan JB, Shen R: High density DNA methylation array with single CpG site resolution. Genomics 2011 , 98:288-295.

12. Sandoval J, Heyn H, Moran S, Serra-Musach J, Pujana MA, Bibikova M, Esteller M: Validation of a DNA methylation microarray for $450,000 \mathrm{CpG}$ sites in the human genome. Epigenetics 2011, 6:692-702.

13. Hon GC, Hawkins RD, Caballero OL, Lo C, Lister R, Pelizzola M, Valsesia A, Ye Z, Kuan S, Edsall LE, Camargo AA, Stevenson BJ, Ecker JR, Bafna V, Strausberg RL, Simpson AJ, Ren B: Global DNA hypomethylation coupled to repressive chromatin domain formation and gene silencing in breast cancer. Genome Res 2012, 22:246-258.

14. Jeong $M$, Sun $D$, Luo M, Huang $Y$, Challen GA, Rodriguez B, Zhang $X$, Chavez L, Wang H, Hannah R, Kim SB, Yang L, Ko M, Chen R, Gottgens B, Lee JS, Gunaratne P, Godley LA, Darlington GJ, Rao A, Li W, Goodell MA:
Large conserved domains of low DNA methylation maintained by Dnmt3a. Nat Genet 2014, 46:17-23.

15. Xie W, Schultz MD, Lister R, Hou Z, Rajagopal N, Ray P, Whitaker JW, Tian S, Hawkins RD, Leung D, Yang H, Wang T, Lee AY, Swanson SA, Zhang J, Zhu Y, Kim A, Nery JR, Urich MA, Kuan S, Yen CA, Klugman S, Yu P, Suknuntha K, Propson NE, Chen H, Edsall LE, Wagner U, Li Y, Ye Z, et al: Epigenomic analysis of multilineage differentiation of human embryonic stem cells. Cell 2013, 153:1134-1148.

16. Stadler MB, Murr R, Burger L, Ivanek R, Lienert F, Scholer A, van Nimwegen E, Wirbelauer C, Oakeley EJ, Gaidatzis D, Tiwari VK, Schubeler D: DNA-binding factors shape the mouse methylome at distal regulatory regions. Nature 2011, 480:490-495.

17. Bert SA, Robinson MD, Strbenac D, Statham AL, Song JZ, Hulf T, Sutherland RL, Coolen MW, Stirzaker C, Clark SJ: Regional activation of the cancer genome by long-range epigenetic remodeling. Cancer Cell 2013, 23:9-22.

18. Coolen MW, Stirzaker C, Song JZ, Statham AL, Kassir Z, Moreno CS, Young AN, Varma V, Speed TP, Cowley M, Lacaze P, Kaplan W, Robinson MD, Clark SJ: Consolidation of the cancer genome into domains of repressive chromatin by long-range epigenetic silencing (LRES) reduces transcriptional plasticity. NatCell Biol 2010, 12:235-246.

19. Mayer W, Niveleau A, Walter J, Fundele R, Haaf T: Demethylation of the zygotic paternal genome. Nature 2000, 403:501-502.

20. Feinberg AP, Tycko B: The history of cancer epigenetics. Nat Rev Cancer 2004, 4:143-153.

21. de la Rica L, Urquiza JM, Gomez-Cabrero D, Islam AB, Lopez-Bigas N, Tegner J, Toes RE, Ballestar E: Identification of novel markers in rheumatoid arthritis through integrated analysis of DNA methylation and microRNA expression. J Autoimmun 2013, 41:6-16.

22. Ziller MJ, Gu H, Muller F, Donaghey J, Tsai LT, Kohlbacher O, De Jager PL, Rosen ED, Bennett DA, Bernstein BE, Gnirke A, Meissner A: Charting a dynamic DNA methylation landscape of the human genome. Nature 2013, 500:477-481.

23. Edgar R, Domrachev M, Lash AE: Gene expression omnibus: NCBI gene expression and hybridization array data repository. Nucleic Acids Res 2002, 30:207-210.

24. Warnecke PM, Stirzaker C, Melki JR, Millar DS, Paul CL, Clark SJ: Detection and measurement of PCR bias in quantitative methylation analysis of bisulphite-treated DNA. Nucleic Acids Res 1997, 25:4422-4426.

25. Sofer T, Schifano ED, Hoppin JA, Hou L, Baccarelli AA: A-clustering: a novel method for the detection of co-regulated methylation regions, and regions associated with exposure. Bioinformatics 2013, 29:2884-2891.

26. Lister R, Pelizzola M, Dowen RH, Hawkins RD, Hon G, Tonti-Filippini J, Nery JR, Lee L, Ye Z, Ngo QM, Edsall L, Antosiewicz-Bourget J, Stewart R, Ruotti V, Millar AH, Thomson JA, Ren B, Ecker JR: Human DNA methylomes at base resolution show widespread epigenomic differences. Nature 2009, 462:315-322.

27. Ball MP, Li JB, Gao Y, Lee JH, LeProust EM, Park IH, Xie B, Daley GQ, Church GM: Targeted and genome-scale strategies reveal gene-body methylation signatures in human cells. Nat Biotechnol 2009, 27:361-368.

28. Lam LL, Emberly E, Fraser HB, Neumann SM, Chen E, Miller GE, Kobor MS: Factors underlying variable DNA methylation in a human community cohort. Proc Natl Acad Sci U S A 2012, 109(Suppl 2):17253-17260.

29. van Eijk KR, de Jong S, Boks MP, Langeveld T, Colas F, Veldink JH, de Kovel CG, Janson E, Strengman E, Langfelder P, Kahn RS, van den Berg LH, Horvath S, Ophoff RA: Genetic analysis of DNA methylation and gene expression levels in whole blood of healthy human subjects. BMC Genomics 2012, 13:636.

30. Chang CW, Cheng WC, Chen CR, Shu WY, Tsai ML, Huang CL, Hsu IC: Identification of human housekeeping genes and tissue-selective genes by microarray meta-analysis. PLoS One 2011, 6:e22859.

31. Portales-Casamar E, Ch'ng C, Lui F, St-Georges N, Zoubarev A, Lai AY, Lee M, Kwok C, Kwok W, Tseng L, Pavlidis P: Neurocarta: aggregating and sharing disease-gene relations for the neurosciences. BMC Genomics 2013, 14:129.

32. Hackett JA, Surani MA: DNA methylation dynamics during the mammalian life cycle. Philos Trans R Soc Lond B Biol Sci 2013, 368:20110328. doi.

33. Sproul D, Meehan RR: Genomic insights into cancer-associated aberrant CpG island hypermethylation. Brief Funct Genomics 2013, 12:174-190.

34. Venter JC, Adams MD, Myers EW, Li PW, Mural RJ, Sutton GG, Smith HO, Yandell M, Evans CA, Holt RA, Gocayne JD, Amanatides P, Ballew RM, Huson DH, Wortman JR, Zhang Q, Kodira CD, Zheng XH, Chen L, Skupski M, Subramanian G, Thomas PD, Zhang J, Gabor Miklos GL, Nelson C, Broder S, Clark AG, Nadeau J, McKusick VA, Zinder N, et al: The sequence of the human genome. Science 2001, 291:1304-1351. 
35. Maunakea AK, Nagarajan RP, Bilenky M, Ballinger TJ, D'Souza C, Fouse SD, Johnson BE, Hong C, Nielsen C, Zhao Y, Turecki G, Delaney A, Varhol R, Thiessen N, Shchors K, Heine VM, Rowitch DH, Xing X, Fiore C, Schillebeeckx M, Jones SJ, Haussler D, Marra MA, Hirst M, Wang T, Costello JF: Conserved role of intragenic DNA methylation in regulating alternative promoters. Nature 2010, 466:253-257.

36. Larsen F, Gundersen G, Lopez R, Prydz H: CpG islands as gene markers in the human genome. Genomics 1992, 13:1095-1107.

37. Zhu J, He F, Hu S, Yu J: On the nature of human housekeeping genes. Trends Genet 2008, 24:481-484.

38. Hansen KD, Langmead B, Irizarry RA: BSmooth: from whole genome bisulfite sequencing reads to differentially methylated regions. Genome Biol 2012, 13:R83.

39. Vanderkraats ND, Hiken JF, Decker KF, Edwards JR: Discovering high-resolution patterns of differential DNA methylation that correlate with gene expression changes. Nucleic Acids Res 2013, 41:6816-6827.

40. Lou S, Lee HM, Qin H, Li JW, Gao Z, Liu X, Chan LL, KI Lam V, So WY, Wang Y, Lok S, Wang J, Ma RC, Tsui SK, Chan JC, Chan TF, Yip KY: Whole-genome bisulfite sequencing of multiple individuals reveals complementary roles of promoter and gene body methylation in transcriptional regulation. Genome Biol 2014, 15:408-014-0408-0.

41. Wu H, Coskun V, Tao J, Xie W, Ge W, Yoshikawa K, Li E, Zhang Y, Sun YE: Dnmt3a-dependent nonpromoter DNA methylation facilitates transcription of neurogenic genes. Science 2010, 329:444-448.

42. Lee TI, Jenner RG, Boyer LA, Guenther MG, Levine SS, Kumar RM, Chevalier B, Johnstone SE, Cole MF, Isono K, Koseki H, Fuchikami T, Abe K, Murray HL, Zucker JP, Yuan B, Bell GW, Herbolsheimer E, Hannett NM, Sun K, Odom DT, Otte AP, Volkert TL, Bartel DP, Melton DA, Gifford DK, Jaenisch R, Young RA: Control of developmental regulators by Polycomb in human embryonic stem cells. Cell 2006, 125:301-313.

43. Yasui DH, Peddada S, Bieda MC, Vallero RO, Hogart A, Nagarajan RP, Thatcher KN, Farnham PJ, Lasalle JM: Integrated epigenomic analyses of neuronal MeCP2 reveal a role for long-range interaction with active genes. Proc Natl Acad Sci U S A 2007, 104:19416-19421.

44. Davis S, Meltzer PS: GEOquery: a bridge between the gene expression omnibus (GEO) and BioConductor. Bioinformatics 2007, 23:1846-1847.

45. Benaglia T, Chauveau D, Hunter DR, Young D: Mixtools: an R package for analyzing finite mixture models. J Stat Softw 2009, 32:1-29. 5.

46. Akalin A, Garrett-Bakelman FE, Kormaksson M, Busuttil J, Zhang L, Khrebtukova I, Milne TA, Huang Y, Biswas D, Hess JL, Allis CD, Roeder RG, Valk PJ, Lowenberg B, Delwel R, Fernandez HF, Paietta E, Tallman MS, Schroth GP, Mason CE, Melnick A, Figueroa ME: Base-pair resolution DNA methylation sequencing reveals profoundly divergent epigenetic landscapes in acute myeloid leukemia. PLoS Genet 2012, 8:e1002781.

47. Varley KE, Gertz J, Bowling KM, Parker SL, Reddy TE, Pauli-Behn F, Cross MK, Williams BA, Stamatoyannopoulos JA, Crawford GE, Absher DM, Wold BJ, Myers RM: Dynamic DNA methylation across diverse human cell lines and tissues. Genome Res 2013, 23:555-567.

48. Bernstein BE, Stamatoyannopoulos JA, Costello JF, Ren B, Milosavljevic A Meissner A, Kellis M, Marra MA, Beaudet AL, Ecker JR, Farnham PJ, Hirst M, Lander ES, Mikkelsen TS, Thomson JA: The NIH roadmap epigenomics mapping consortium. Nat Biotechnol 2010, 28:1045-1048.

49. Price ME, Cotton AM, Lam LL, Farre P, Emberly E, Brown CJ, Robinson WP, Kobor MS: Additional annotation enhances potential for biologically-relevant analysis of the Illumina Infinium Human Methylation 450 Bead Chip array. Epigenetics Chromatin 2013, 6:4.

50. Guttman M, Amit I, Garber M, French C, Lin MF, Feldser D, Huarte M, Zuk O, Carey BW, Cassady JP, Cabili MN, Jaenisch R, Mikkelsen TS, Jacks T, Hacohen N, Bernstein BE, Kellis M, Regev A, Rinn JL, Lander ES: Chromatin signature reveals over a thousand highly conserved large non-coding RNAs in mammals. Nature 2009, 458:223-227.

51. Zoubarev A, Hamer KM, Keshav KD, McCarthy EL, Santos JR, Van Rossum T, McDonald C, Hall A, Wan X, Lim R, Gillis J, Pavlidis P: Gemma: a resource for the reuse, sharing and meta-analysis of expression profiling data. Bioinformatics 2012, 28:2272-2273.

52. Lee HK, Braynen W, Keshav K, Pavlidis P: ErmineJ: tool for functional analysis of gene expression data sets. BMC Bioinformatics 2005, 6:269

53. Gillis J, Pavlidis P: The impact of multifunctional genes on "guilt by association" analysis. PLoS One 2011, 6:e17258.

doi:10.1186/1756-8935-7-28

Cite this article as: Edgar et al:: Meta-analysis of human methylomes reveals stably methylated sequences surrounding CpG islands associated with high gene expression. Epigenetics \& Chromatin 2014 7:28.

\section{Submit your next manuscript to BioMed Central and take full advantage of:}

- Convenient online submission

- Thorough peer review

- No space constraints or color figure charges

- Immediate publication on acceptance

- Inclusion in PubMed, CAS, Scopus and Google Scholar

- Research which is freely available for redistribution

Submit your manuscript at www.biomedcentral.com/submit
C) BioMed Central 